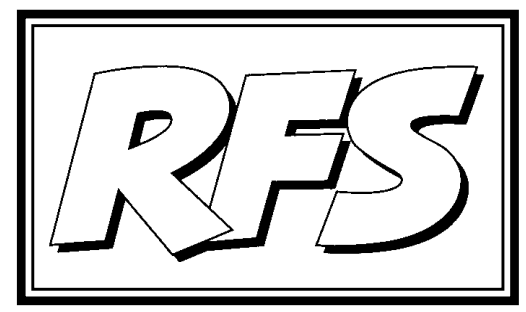

Revista de Fomento Social, 61 (2006), 499-517

\title{
La responsabilidad social de la empresa: ¿el coste de tener conciencia?
}

\section{Consejo de Redacción}

(PALABRAS CLAVE: Responsabilidad SOCIAL, Modelo DE EMPRESA, "STAKEHOLDERS", DERECHOS SOCIALES.

KEY WORDS: SOCIAL RESPONSIBILITY, MODEL OF COMPANY, STAKEHOLDERS, SOCIAL RIGHTS)

El 4 de agosto de 2006 publicaba el Boletín Oficial de las Cortes Generales el Informe de la Subcomisión para potenciar y promover la responsabilidad social de las empresas, aprobado el día 27 de julio por unanimidad en la Comisión de Trabajo y Asuntos Sociales ${ }^{1}$. Es una iniciativa que confirma la

1 El informe, que es de una extensión considerable, puede verse en Boletín Oficial de las Cortes Generales. Congreso de los Diputados n. 424 (4 agosto 2006) 3-120. 
impresión de que el tema tiene una indudable actualidad. Cabría decir, si se nos permite, que está de moda.

También en nuestra institución, ETEA, ha surgido un grupo formado por docentes que investigan esta área con especial dedicación, en el marco de las líneas prioritarias derivadas de la misión social de la institución. Desde hace año y medio viene actuando en distintos frentes, uno de los cuales ha sido la colaboración desinteresada y generosa para la elaboración de las reflexiones que siguen ${ }^{2}$. Nuestra misma Revista de Fomento Social ha tratado recientemente, de forma reiterada, el tema mediante trabajos de algunos de nuestros colaboradores ${ }^{3}$.

La responsabilidad social es algo más que una moda. Responde a ciertas demandas de la sociedad, y no sólo del mundo empresarial. Pero corre también sus peligros. No es el último de ellos el de convertirse en un tópico: llegamos así a una situación en que el concepto mismo de responsabilidad social queda tan desvaído y carente de perfiles nítidos que más parece un "cajón de sastre" al que se recurre para todo.

El esquema que hemos adoptado en esta reflexión es el siguiente: comenzamos preguntándonos por qué este tema reviste hoy un interés tan difundido, deteniéndonos en los dos fenómenos que consideramos clave para ello: la globalización y la crisis del Estado social; en segundo lugar analizamos brevemente la historia y la evolución del concepto desde las viejas preocupaciones caritativas hasta los planteamientos recientes centrados en la consideración

2 A todos ellos queremos manifestar desde aquí nuestra gratitud por esa disponibilidad: a los profesores Carmen Bustos, Luis Amador, Pilar Tirado y Mercedes Ruiz, pero especialmente a los coordinadores del grupo, los profesores Rafael Araque y $\mathrm{M}^{\mathrm{a}}$ José Montero.

3 Cfr. R. Araque Padilla (2002), "Una aportación al debate sobre el Libro Verde de la responsabilidad social de la empresa", Revista de Fomento Social, vol. 57, n 228, octubre-diciembre, 595-628; I. Camacho LaRaña (2004), "La responsabilidad social de la empresa: un proceso abierto", Revista de Fomento Social, vol. 59, nº 233, enero-marzo, 75-98; R. Araque Padilla (2004), "Factores condicionantes de la responsabilidad social de la empresa: los límites de lo posible", Revista de Fomento Social, vol. 59, n 235, julio-septiembre, 553-591; M. CAMPRODOn Rosanas - J. Sols LuCiA - A. FloRensa GimÉnEz (2006), "Las agencias de evaluación de la Responsabilidad Social Corporativa: estudio de un caso", Revista de Fomento Social, vol. 59, $\mathrm{n}^{\mathrm{o}} 243$, julio-septiembre, 393-421. A los temas de ética empresarial, dedicamos en fechas relativamente más lejanas dos editoriales, aunque la expresión "responsabilidad social" no aparezca en el título: CONSEJO DE REDACCIÓN (1997), "La ética empresarial: ¿necesidad, utilidad o pretexto?", Revista de Fomento Social, vol. 52, n⿳ 208, octubre-diciembre, 459-475; ConsEJo DE REDACCIÓN (2000), "Empresa y sociedad: interrogantes éticos", Revista de Fomento Social, vol. $55, \mathrm{n}^{\circ}$ 217, enero-marzo, 13-28. 
de los llamados stakeholders; el apartado tercero intenta precisar y acotar un poco más el propio concepto de responsabilidad social, para evitar un marco de comprensión de tal amplitud que resulte, por ello mismo, poco operativo; a continuación, llamamos la atención sobre los peligros que oculta la generalización del concepto de responsabilidad social que, a fuerza de repetirse, puede terminar convirtiéndose en un tópico; en el apartado 5 nos preguntamos por la eficacia real de la responsabilidad social, para detenernos luego en lo que llamamos la "agenda pendiente", o tareas abiertas y líneas en las que habría que trabajar todavía para avanzar en esta cuestión; por último, acabamos con unos breves párrafos conclusivos sobre el marco último de comprensión de la responsabilidad social de la empresa.

\section{1. ¿Oportunidad, moda, necesidad?}

El citado informe parlamentario afirma que la Subcomisión, creada por el Pleno del Congreso de los Diputados a propuesta del Grupo Parlamentario Catalán de Convergencia i Unió, "deberá estudiar las nuevas tendencias vinculadas a la asunción de los principios de la responsabilidad social por parte de las empresas con el fin de proponer un conjunto de medidas al Gobierno al objeto de potenciar y promover la responsabilidad social de las empresas"4. Se pretende, por tanto, que el Gobierno intervenga "potenciando y promoviendo", pero se reconoce para ello la conveniencia de analizar previamente el estado de la cuestión. También nosotros quisiéramos haceralgo de eso preguntándonos por qué hoy el tema reviste un interés tan difundido.

Decir simplemente que es una moda nos resulta demasiado banal. ¿No hay detrás de esta moda algunos factores que explican el interés que se ha suscitado?

Nos atreveríamos a indicar dos, que marcan la evolución de nuestra sociedad en el paso del siglo XX al siglo XXI: la crisis del Estado social y la globalización. En realidad son dos fenómenos en modo alguno independientes entre sí, pero tampoco se puede reducir sin más el uno al otro.

Entre los efectos más significativos de la globalización está la creciente impotencia de los gobiernos para controlar la marcha de la economía, incluso la del propio país. Y simultáneamente asistimos a un poder también creciente de las empresas en ese mercado mundial cada vez más integrado al que los

$4 \quad$ L. C., 4. 
procesos globalizadores van abriendo paso. Si la globalización es ante todo un proceso de integración progresiva, aunque desigual y selectiva, de todos los mercados, este fenómeno esencialmente económico tiene indudable consecuencias políticas. Y entre ellas se cuenta esta pérdida de capacidad de los gobiernos, a los que falta el punto de apoyo esencial para ejercer sus funciones: el control del territorio encuadrado dentro de sus fronteras.

Aunque no podamos hablar de una correspondencia exacta porque habría otras variables a tener en cuenta, puede decirse que el poder de las empresas aumenta en la misma medida en que disminuye el de los gobiernos. Algunos grandes escándalos de los últimos años han servido para una toma de conciencia mundial de hasta dónde puede llegar el poder incontrolado de las grandes empresas. Basta citar a Enron. Se impone la convicción de que la responsabilidad es correlativa al poder de que se dispone. En palabras de Mitchell ${ }^{5}$ : "No es una cuestión de que las empresas decidan ser socialmente responsables. Son responsables". De muchas cosas que ocurren en nuestro mundo, en nuestros mercados, son responsables las empresas. Se trata de que asuman esa responsabilidad.

$Y$ es que el Estado ya no tiene las mismas posibilidades de controlar esa responsabilidad. Esta pérdida de capacidad de intervención a base de medidas legales y administrativas, es consecuencia de la globalización, pero también tiene que ver con la crisis del Estado social. Se dice que esta crisis es consecuencia de la globalización, y las reflexiones que preceden pueden conducir a esa conclusión. Pero existen también factores endógenos, derivados de su propia dinámica, que aportan nuevos elementos para explicar su crisis persistente.

Porque el Estado social había generado una cierta "división del trabajo" encomendando lo público al Estado y reservando a la sociedad el ámbito de lo privado. Mientras existiera un Estado capaz de garantizar los intereses generales de la sociedad, los particulares podemos dedicarnos en cuerpo y alma a nuestros propios intereses. Pero esta separación tan tajante se ha revelado ineficiente porque ha dejado al Estado demasiado aislado y solitario a la hora, no sólo de atender a esas demandas de lo público, sino de corregir los efectos negativos de una sociedad tan desentendida de los intereses de todos. El desarrollo creciente en estos últimos años del sector de organizaciones sin ánimo de lucro puede interpretarse como una respuesta de la sociedad para hacer

5 Mitchell, A. (1998), "Business pays the price for having a conscience", Marketing Week, 10 de diciembre, pp. 38-39. Se observará que el subtítulo que hemos escogido para nuestro editorial parafrasea el título de este artículo. 
frente a estos problemas. Pero ha llegado el momento también de reclamar a las empresas que salgan de ese ensimismamiento derivado de moverse sólo en el ámbito de sus intereses económicos y lucrativos.

Abundando todavía en las consecuencias que tiene para la empresa esta nueva situación cabe decir que asistimos a una cierta crisis de legitimidad de la empresa ante la sociedad. Aquella no puede ampararse en hechos tales como la presión competitiva que acarrea la globalización, por muy indudable que sea, para justificar cosas como: el aumento de la inseguridad y la precarización del trabajo, la creciente desigualdad en los abanicos salariales y su inacción para promover la igualdad de oportunidades, los problemas surgidos en el gobierno de las organizaciones, el detrimento del entorno, un cierta colonización de los espacios culturales y políticos y de la vida privada en general, el incumplimiento tantas veces de los derechos humanos derivado de la obsesión por reducir los costes para ser más competitivos o para obtener mayores ganancias.

En resumen, globalización y crisis del Estado social son el terreno abonado para que haya ido surgiendo en la sociedad, y también en el mismo mundo empresarial, una demanda convertida cada vez más en exigencia inaplazable: la empresa tiene que hacer frente responsablemente a las consecuencias de sus actuaciones en todos los ambientes, y no refugiarse diciendo que su función social es producir bienes y servicios y generar lucro para sus propietarios. Ahora se ve más claro lo que afirmábamos antes: que la responsabilidad no es una opción, es un hecho. La preocupación por la responsabilidad social de la empresa sólo busca que ese hecho sea asumido por aquellos a quienes corresponde, es decir, por las empresa mismas.

\section{No es un tema de hoy: tiene su historia}

Evidentemente no estamos sólo ante una moda. Hemos visto que responde a una necesidad. Ahora queremos añadir que tampoco es un tema exclusivamente de hoy. Tiene su historia.

Como consecuencia de esta historia, lo primero que han tenido que hacer los promotores de este concepto es superar una cierta tradición en lo que se entendía como responsabilidad social de la empresa. Porque allá por el siglo XVIII y buena parte del XIX hablar de responsabilidad social era referirse a la "caridad de los propietarios". Eran los tiempos del capitalismo puro de mercado, del capitalismo salvaje, cuando la empresa buscaba su beneficio, o la mera supervivencia, sin reparar apenas en medios: horarios inhumanos, trabajo sin 
consideración de los niños, salarios insuficientes y no sometidos a ninguna regulación, insalubridad de los lugares de trabajo; en una palabra, miseria generalizada en las clases obreras industriales. Todo ello -se decía- como consecuencia de las férreas leyes del mercado.

Es en ese contexto donde algunos grandes empresarios destinaban una parte de sus ganancias suculentas para "obras sociales”. Sus beneficiarios solían ser las mismas víctimas del sistema: víctimas unas veces directas (mutuas, asociaciones de trabajadores) y otras indirectas (obras sociales o de caridad, que fueron por otra parte precedente de iniciativas sociales de gran alcance en tiempos posteriores). Pretendían así contrarrestar los efectos perniciosos de las estructuras económicas con comportamientos individuales basados en actitudes de indudable misericordia, pero no exentas de paternalismo. Los oponentes del sistema los acusaron, no siempre sin razón, de querer "poner paños calientes" a un modelo económico en sí mismo injusto e inaceptable. Para otros este paternalismo era una estrategia para evitar que el Estado interviniera con regulaciones que limitaran la libertad económica.

Ahora bien, para seguir el rastro de modo más riguroso a la génesis del concepto de responsabilidad social de la empresa hay que examinar la concepción misma de la empresa. Aunque esto pudiera parecer a algunos una elucubración inútil, estamos convencidos que la idea que se tiene de empresa, de su función y de sus objetivos, es decisiva para entender cómo la empresa de hecho funciona y con qué criterios se dirige. Y esta idea de empresa, que los estudiosos perfilan, analizan e intentan justificar, está presente, aunque sea de modo inconsciente, en el comportamiento empresarial de todos. Es este un enfoque que nos permite descubrir la dimensión ética de la actividad empresarial, no entendiendo la ética como algo extrínseco a la realidad de la empresa, sino viéndolo como algo inherente a esa misma realidad.

A fuerde ser excesivamente simplificadores con los hechos, nos permitiríamos presentar tres modelos de empresa, que se han sucedido en el último siglo. Sin duda habrá muchos más, pero estos tres son suficientes para vislumbrar cómo el concepto de responsabilidad social se ha ido configurando.

Tomamos como punto de partida la visión de la empresa como unidad de producción, donde capital y trabajo se dan cita para producir unos bienes y servicios según demanda del mercado, generando así un valor añadido a repartir entre ambos factores. Este modelo, que es clásico en muchos libros de economía muy usados en universidades y centros de estudio, visualiza perfectamente los grandes conflictos de la sociedad industrial en la época del 
capitalismo liberal. La Doctrina Social de la Iglesia está también muy marcada por estos planteamientos en toda su primera etapa, hasta la época de Pablo VI por los menos. La preocupación ética fundamental-compartida también por la Iglesia- era el alcanzar un equilibrio aceptable entre ambos colectivos, de forma que se respetasen los derechos de las dos partes; se prestaba además una atención preferente a la parte más débil y vulnerable (el factor trabajo). Es en este contexto también donde se consiguió la conquista de los principales derechos vinculados al trabajo, un hecho de mucha trascendencia que de ningún modo conviene pasar por alto.

Pero este enfoque comenzó a ser cuestionado en la década de 1940 en lo que se conoció como la revolución de los directivos ${ }^{6}$. Frente a la lucha por poner la empresa al servicio de los intereses de los propietarios del capital o de los trabajadores surge la propuesta de que la empresa es una entidad autónoma, que tiene su propia dinámica y que no siempre coincide en sus objetivos con lo que pretenden de ella los factores de producción. Son entonces los directivos empresariales los que se erigen en protagonistas fundamentales, porque a ellos corresponde representar y garantizar los intereses autónomos de la empresa, y defender a ésta de los intentos de instrumentalización de capital y trabajo. Será preocupación de ellos mostrar que los intereses de la empresa coinciden a la larga con los de estos dos grupos, pero en el corto plazo esto no siempre resultará evidente para todos. Naturalmente para hacer efectiva esta misión los directivos reclamarán poder y autonomía, que irán conquistando de hecho aunque sin modificar el marco legal de la empresa capitalista (la sociedad por acciones).

Pero, sólo unas décadas después, comienza a sospecharse que la revolución de los directivos ha llegado demasiado lejos. Toca ahora el turno a los accionistas, que se quejan de su postergación y reclaman el protagonismo que les corresponde en virtud de su condición de propietarios. Por eso -y en contraposición con la revolución anterior-ahora comienza a hablarse de la revolución de los accionistas. Milton Friedman lo expresó con meridiana claridad en un artículo infinitamente citado, donde pretende precisamente pronunciarse sobre lo que debe entenderse por responsabilidad social de la empresa ${ }^{7}$. En su opinión, ésta no consiste sino en alcanzar lo que sus propietarios desean: hacer rentable un patrimonio, y cuanto más rentable mejor. Con palabras de Friedman:

6 El nombre procede de la obra de J. BuRnham, The Managerial Revolution, publicada en 1941.

7 Este pasaje está tomado de un artículo publicado en The New York Times Magazine, el 13 septiembre 1970, que llevaba por título: The social responsabilility of business is to increase its profits. 
En un sistema de libertad de empresa y propiedad privada, un ejecutivo es un empleado de los propietarios del negocio. Es directamente responsable ante sus patronos. Esa responsabilidad consiste en dirigir el negocio de acuerdo con los deseos de aquéllos, que generalmente se reducirán a ganar tanto dinero como sea posible siempre que se respeten las reglas básicas de la sociedad, tanto las prescritas por la ley como por la costumbre moral.

Esta postura de Friedman es una buena expresión de la teoría de la agencia: los ejecutivos de una empresa no son sino agentes de los propietarios, que obran por cuenta de aquellos y como delegados de ellos para obtener los objetivos que dichos mandatarios desean.

Esta teoría de la agencia llevada a su extremo -y así nos situamos ya en el presente-reduce la empresa a un patrimonio rentable: de ella lo que interesa no es tanto la producción de bienes y servicios, y la aportación insustituible que eso representa para la sociedad, sino el capital financiero que estâ detrás y su potencial rentabilidad. La búsqueda de rentabilidad no es lo nuevo de esta concepción, sino la progresiva desconexión entre producción y rentabilidad y el convencimiento de que el capital es más rentable en operaciones financieras que en iniciativas estrictamente productivas. Como consecuencia, la economía financiera impone su ley sobre la economía real. Aquella deja de ser complemento de ésta para convertirse en el verdadero fin de la actividad económica, a la que la economía real no tiene más remedio que subordinarse.

Por este camino ¿no termina por perder su verdadero sentido y por desvirtuarse la actividad económica? Los excesos a que han llegado no pocas empresas importantes muestran de modo terminante que las reservas ante ese modo de entender la empresa no eran injustificadas. Y es ahí donde resurge con un sentido nuevo el concepto de responsabilidad social, como denuncia de los efectos negativos que esas ideas dominantes están produciendo y como búsqueda de nuevos modelos de análisis.

Una buena contribución para dar forma a estas preocupaciones llegó desde el concepto de stakeholders, que en realidad procedía del ámbito de la investigación estratégica. Pero es de justicia reconocer que ha prestado un excelente servicio a la ética para dar contenido a la responsabilidad social de la empresa. Como es sabido, el término stakeholders había sido puesto en circulación por $R$. E. Freeman en los años $1980^{8}$. La palabra no es fácil de traducir a nuestra lengua -al no haberse impuesto una traducción única en castellano optamos,

8 R. E. FreEman (1984), Strategic Management: a Stakeholders Approach, Boston. 
como hace la mayoría, por mantener el término inglés-. Stakeholders son considerados aquellas personas o grupos con los que la empresa está implicada. Esta definición incluye dos tipos de stakeholders: los pasivos y los activos, aquellos que pueden ser afectados por la actividad de la empresa y aquellos que pueden afectar al desarrollo de las actividades de la empresa.

Es claro que con esta nueva perspectiva se amplían los grupos a tener en consideración superando el reduccionismo de Friedman. No sólo a los stockholders hay que atender (como pretendiera Friedman), sino a todos los stakeholders entre los que se encuentran también los accionistas.

La enumeración de los diferentes stakeholders puede ser larguísima. Los más evidentes: propietarios y trabajadores, consumidores y proveedores, administración pública y sociedad, entorno inmediato y medio ambiente en general. No nos detenemos en esta cuestión. Lo relevante es subrayar cómo de las relaciones recíprocas con esos grupos emergen diferentes dimensiones de la responsabilidad que la empresa tiene hacia la sociedad y sus componentes en el sentido que indicábamos más arriba: existe una relación recíproca, en ella la empresa actúa con un indudable poder, y ese poder implica una responsabilidad que la empresa no puede ignorar. La responsabilidad social, hacia diferentes colectivos sociales, existe. $Y$ no puede ser algo sobreañadido o que se oriente a otros colectivos ajenos a la empresa (asistencialismo social): su objeto han de ser los colectivos con los que la empresa está en interacción.

\section{Es conveniente precisar más el concepto}

Si la consideración de los stakeholders ofrece una buena vía para delimitar $y$ definir lo que es la responsabilidad social, algunos ven en ese abanico de grupos colectivos como un mapa panorámico de lo que es la ética empresarial sin más. No hay, sin embargo, que confundir ambas cosas: sin duda que la ética es el valor que inspira los comportamientos socialmente responsables; ahora bien, se puede ser ético sin ser consciente de la responsabilidad social y se puede ser socialmente responsable cumpliendo los estándares fijados en diferentes propuestas, pero de una manera poco ética (v.gr., con baja participación de los trabajadores en los problemas que les afectan, o pagando salarios a todas luces injustos).

La dificultad para estableceruna definición más precisa de la responsabilidad social proviene de la misma ambigüedad de las dos palabras, responsabilidady social. En la mejor tradición de la filosofía española (Ortega, Zubiri, Aranguren) 
la responsabilidad se relaciona directamente con la libertad. Si el animal tiene su conducta "ajustada" a los instintos, al ser humano le corresponde ajustar su comportamiento a los otros desde la libertad, a la vista de las distintas alternativas que se le abren. Ser responsable es ser capaz de responder de lo que hemos hecho o dejado de hacer entre las posibilidades que se nos presentaban. La responsabilidad supone entonces una perspectiva ética abierta, no encerrada en normas, donde la relación con el otro es esencial: si clásicamente esta relación se ha centrado en los más próximos (el "prójimo"), hoy se amplía también a los más lejanos como efecto de la conciencia de vivir en un mundo cada vez más estrecho de relaciones ${ }^{9}$.

Cuando se habla de responsabilidad social hay que pensar siempre en la capacidad de responder ante la sociedad. Puede parecer que esta precisión aclara poco porque la sociedad es una realidad demasiado compleja y variada. Pero, por el afán de precisar, no perdamos de vista que la principal virtualidad del concepto de responsabilidad social es precisamente su pretensión de amplitud, de no reduccionismo ni de exclusión.

Sin embargo en la práctica este concepto se ha hecho más restrictivo, concentrando la atención en algunos stakeholders, aquellos a los que por distintas razones parece en este momento más decisivo atender. Este reduccionismo tiene la ventaja de aumentar la concreción, pero el peligro de olvidar definitivamente a los que de momento se excluyen de esa atención preferente.

Concretamente son dos los stakeholders a los que hoy se presta más atención: los trabajadores y el medio ambiente. No son razones teóricas las que justifican esta elección, sino más bien consideraciones prácticas: la precarización creciente del trabajo, a la que ya nos hemos referido, y la alarma ante un uso desmedido de los recursos naturales. En ambos casos la globalización, y la competencia que de ella resulta, hacen de los trabajadores y de la naturaleza las variables más frecuentemente manejadas para reducir costes y situarse con más desahogo en el mercado unificado.

Un ejemplo significativo de esta forma de dar contenido (y de definir) la responsabilidad social la tenemos en la Unión Europea. En el Libro Verde publicado en 2001 con el objetivo de abrir un debate sobre el tema se afirma:

9 La obra de Hans Jonas, El principio de responsabilidad: Ensayo de una ética para la civilización tecnológica, cuya edición original data de 1973, ha sido decisiva en esa ampliación de la responsabilidad hasta dimensiones cósmicas. 
La mayoría de las definiciones de la responsabilidad social de las empresas entienden este concepto como la integración voluntaria, por parte de las empresas, de las preocupaciones sociales y medioambientales en sus operaciones comerciales y sus relaciones con sus interlocutores ${ }^{10}$.

Esta forma de concretar lo que es la responsabilidad social se ha erigido en punto de referencia no sólo en Europa y ha dado lugar a aplicaciones ulteriores buscando medios para cuantificar la responsabilidad en esos dos campos.

Todavía se puede avanzar algo más en el alcance y características de la responsabilidad social con los tres puntos que siguen ${ }^{11}$.

1. Se trata de un concepto dinámico. Lo esencial en ella no es la aplicación mecánica de principios establecidos a priori, o el establecimiento por anticipado de una serie de obligaciones a las que hay luego que responder en la práctica. Esas obligaciones deben ser descubiertas en la experiencia de cada día desde una actitud de discernimiento de los aspectos en que está en juego esa responsabilidad. Algunos autores hablan en este sentido de una postura orientada, más que a resultados, a procesos ${ }^{12}$.

2. Se trata también de una actitud proactiva. No basta responder a las demandas que proceden de la sociedad, es preciso anticiparse y adelantarse a ellas. Esto es lo que algunos autores llaman responsividad (responsiveness).

3. Está ligado a la legitimidad social de la empresa. Esta ya no se legitima ante la sociedad sólo a través de tareas productivas, porque la conciencia del multiforme impacto de la empresa sobre la sociedad está cada vez más difundido y lleva a estas exigencias que se insertan dentro de la responsabilidad social.

Otra dificultad para delimitar lo que se entiende por responsabilidad social deriva de los términos que se relacionan con ella. Al menos conviene mencionar dos. La responsabilidad social no debe reducirse al gobierno corporativo o al

10 Comisión de las Comunidades Europeas (2001), Libro verde. Fomentar un marco europeo para la responsabilidad social de las empresas, Bruselas.

11 Nos inspiramos en el citado Informe promovido por el Parlamento español (cf. supra), que, en su intento de definir la responsabilidad social, recoge las posiciones de muchos de los comparecientes de las que entresaca algunos aspectos relevantes que nosotros nos hemos permitido reelaborar. L. c. 13-20.

12 P. Maclagan (1999), “Corporate social responsibility as a participative process”, Business Ethics 8, n. 1 (January) 43-49 
"buen gobierno": con éste se hace referencia a la transparencia en las actuaciones y en la composición de los órganos de gobierno, pero eso responde más bien todavía al enfoque de la teoría de la agencia. Y tampoco debe reducirse la responsabilidad social a acción social o asistencial, que suele aplicarse a la realización de actuaciones de apoyo a colectivos desfavorecidos de manera continuada y como parte de la estrategia empresarial de responsabilidad: la acción social puede ser un instrumento de la responsabilidad social, pero no el único ni el más representativo, ya que se refiere a colectivos que sólo indirectamente están afectados por la actividad de la empresa.

\section{Los peligros de un tópico}

Quizás hasta este momento nuestras reflexiones han resultado demasiado académicas y menos comprometidas. No es esa nuestra intención, tratándose de un artículo editorial, en el que la Revista de Fomento Social acostumbra a tomar posición en relación con temas de actualidad. En realidad precisar los conceptos es ya una forma de tomar posición, porque la imprecisión y la ambigüedad sirven para encubrir usos incorrectos y espurios de las palabras. $Y$ eso es tanto más frecuente cuanto más extendido es el uso de los términos. A eso nos referimos cuando colocamos la palabra "tópico" en el epígrafe de este apartado. Un tópico es un lugar común, al que usualmente todos recurrimos. No tiene, en principio, ningún sentido peyorativo: indica algo que nos es familiar. Pero esta generalización no carece de peligros. A algunos de ellos queremos referirnos. No tienen nada de teóricos, sino que son expresión de tendencias que un observador atento de la realidad económica y empresarial entrevé o percibe abiertamente en muchas iniciativas.

El primer peligro es el del reduccionismo. En nuestro encomiable afán por concretar, nos limitamos a algunos pocos aspectos -ya los hemos indicado, lo sociolaboral y lo medioambiental-y nos desentendemos de todos los demás. Se nos antoja que otros aspectos no deberían ser tan marginados. Llama la atención el olvido sistemático de dos stakeholders:

- Es escasa la consideración con los consumidores, reales o potenciales. Y sin embargo en sociedades de consumo elevado como las nuestras con una elevada capacidad de compra pero también de producción, el papel de las empresas como promotores de sus productos es decisivo. No vamos a entrar en las cuestiones que suscita la publicidad, sus mecanismos y sus estrategias. ¿Es aventurado decir que los derechos del consumidor son muchas veces poco respetados, cuando no abiertamente atacados? 
¿No están lejos los códigos de publicidad de lo que vemos cada día en la pequeña pantalla y en otros escaparates publicitarios?

- En la responsabilidad social está casi inédita la relación con la administración pública. Con frecuencia ni aparece en la lista de los implicados o afectados. ¿No subyace aquí toda una visión de las relaciones entre el sector privado y el público, según la cual lo público viene a ser más un obstáculo a esquivar que un complemento para la actividad de la empresa? Esto afecta al comportamiento y a las actitudes de las empresas en relación con las normas jurídicas o las obligaciones fiscales.

Un segundo peligro es el del pragmatismo: reducirse sólo a aquello que es medible y cuantificable. No podemos ignorar la intención que hay detrás de este deseo por lo cuantificable: que no nos contentemos con las palabras altisonantes, sino que nos arriesguemos a medir y comparar distintas mediciones. Pero es evidente que no todo se puede medir, que hay intangibles que no se prestan a ser cuantificados, o sólo al precio de desvirtuarlos o prescindir de sus componentes más sustanciales.

El peligro que podíamos llamar del encubrimiento tiene que ver con los dos anteriores, pero va más lejos. Conecta con el escepticismo que muestran muchos ante cualquier discurso proveniente del mundo empresarial y económico que verse sobre ética o responsabilidad social. Y responde a la experiencia generalizada de la corrupción que impregna a tantas actividades en estos campos, y que sólo en casos muy escandalosos, o bajo el impulso de intenciones poco confesables de los delatores, salen de vez en cuando a la luz pública y a los medios de comunicación. Tanto hablar de códigos éticos y de responsabilidad social ¿no será sino una forma de ocultar o de disimular prácticas éticamente inadmisibles? ¿no será una forma de crear una falsa confianza en el ciudadano para bloquear su capacidad de crítica o desactivar todo deseo de controlar al mundo económico? ¿no será una estrategia que sólo busca vender imagen? A veces se tiene la impresión de que, mientras más se difunden ideas, documentos e iniciativas sobre responsabilidad social, mayores y más sorprendentes son los casos de flagrantes injusticias y atropellos. Y sin llegar a grandes escándalos, la responsabilidad social insiste en los derechos laborales, pero el trabajo cada vez es más precario e inhumano; y del respeto al medio ambiente cabría decir algo parecido.

También se puede dar la vuelta a esta argumentación tan pesimista y decir: si hablando tanto de responsabilidad social las cosas van tan mal, ¿qué sería si ni siquiera se hablase de ella? En todo caso admitamos que esta temática contribuye 
a crear y a dar cauce a una conciencia en la sociedad, que frena la tendencia natural de muchos a desentenderse de todo este mundo como una realidad tan incontrolable que ya hasta los poderes públicos resultan impotentes para intervenir, cuando no se encuentran también envueltos en las redes de la corrupción.

Así se pone de manifiesto que los grandes problemas de nuestra sociedad no se pueden resolver ya sólo en la dialéctica de mercado y Estado, de economía y política, porque cada vez se hace más precisa la intervención de la sociedad civil como instrumento de control de una y otra. ¿No es éste el sentido más profundo de la democracia?

Un cuarto y último peligro que quisiéramos mencionar es, en algún modo, opuesto a todo lo que precede: el peligro del utopismo. Es cierto que tras muchas manifestaciones sobre la responsabilidad social se tiene la impresión de estar oyendo hablar más de un mundo de ángeles que de seres humanos. Normalmente es un discurso cargado de bellas e ideales formulaciones, pero tan abstractas y genéricas que no llegan nunca a pisar el suelo de nuestras realidades. Este peligro siempre ha acechado a la ética, a la general y sobre todo a la aplicada, cuando se elabora desde puros principios y se rehuye entrar en el análisis de esa realidad tan compleja que son las actividades profesionales. Precisamente la amplitud semántica de las dos palabras que se juntan en la expresión "responsabilidad social" se presta a derivar en grandes afirmaciones y ambiciosos principios que, no sólo contrastan con la realidad prosaica de cada día, sino que privan al concepto mismo de toda operatividad y despojan de toda credibilidad a sus promotores.

\section{De la teoría a la práctica}

Los peligros enumerados no son suficientes para negar la trascendencia de la responsabilidad social para inspirar las actividades empresariales en nuestro mundo globalizado. Pero, ante todas estas propuestas teóricas, muchos se hacen la pregunta lógica: ¿qué incidencia tiene todo esto en la vida real de las empresas? Es un valor indiscutible que el tema esté siendo objeto de un amplio debate y que suscite el interés de numerosas personas e instituciones. Pero eso solo no basta. Es preciso pasar de la teoría a la praxis.

Es mâs, hay muchos escépticos respeto a la eficacia real de la responsabilidad social corporativa. Quizás las más frecuentes son las denuncias relativas a la dimensión social. Falta de respeto de los derechos sociales, precariedad de los salarios y de las condiciones de trabajo, insuficiencias en la prevención de 
riesgos laborales que se traducen en continuos accidentes de trabajo e incluso muertes: he ahí críticas que desgraciadamente estamos muy habituados a escuchar. Pero tampoco hay que ignorar las dificultades de tantas empresas para respetar los límites que impone el Protocolo de Kyoto: aunque las denuncias sobre abusos en temas de contaminación medioambiental tengan eco mediático menor, no por ello son menos preocupantes.

Con todo, no se pueden generalizar los casos de infracciones. Además, al mismo tiempo hay que valorar el hecho de que la responsabilidad social va incorporándose cada vez más a la cultura empresarial. Y esto es tanto más necesario decirlo cuanto que la normalidad nunca es noticia $y$, por eso, no sirve para contrarrestar los abusos que frecuentemente saltan a los medios.

Más aún, la responsabilidad social es preocupación no sólo para las grandes empresas y para las multinacionales, que fueron quizás las que iniciaron este movimiento y sin duda las que le han dado más publicidad. Hoy existe un encomiable esfuerzo por parte también de las PYME, cada vez más convencidas que esta cuestión tampoco para ellas puede ser opcional. Por último, no conviene olvidar el interés de las organizaciones no lucrativas y no gubernamentales. En principio parecería que ellas serían las más dispuestas a ocuparse de estas cuestiones, precisamente porque no se mueven por motivos de lucro. En todo caso, la responsabilidad social es además un espacio adecuado de encuentro y convergencia entre las organizaciones lucrativas y las que no lo son, que ayudará a reducir la excesiva e injustificada contraposición que muchas veces se establece entre unas y otras.

Otra cuestión muy práctica que se plantea también con frecuencia es la de los costes de esta opción: ¿resulta más caro, menos rentable, aceptar los compromisos inherentes a la responsabilidad social? Es lógico que el ejecutivo de una empresa o el inversor se hagan esta pregunta.

Si se nos pide que respondamos directamente a la pregunta, tendríamos que hacerlo matizando. Cabría decir que la responsabilidad social es rentable a largo plazo: mejora la imagen y aumenta la reputación de la empresa, gana nuevos segmentos de "consumidores éticos", etc. En el corto plazo es más difícil afirmar esa rentabilidad, sobre todo si se tiene como punto de comparación a empresas que cifran su éxito en operaciones de carácter especulativo que se aprovechan además del factor sorpresa y no consideran un valor la permanencia en el tiempo y la consolidación en el mercado. Pero esa forma rápida de "hacer dinero" es criticable por otras muchas razones, en las que no podemos entrar ahora. 
Pero la pregunta por la rentabilidad de la responsabilidad social puede abordarse, no sólo buscando una respuesta, sino cuestionando lo que puede ocultarse tras ella. Porque no sería de recibo ver en la rentabilidad la razón fundamental para incorporar a la empresa la responsabilidad social. La rentabilidad no puede ser la finalidad de la responsabilidad social: en todo caso, sería una de sus consecuencias. Lo contrario sería caer en una instrumentalización de la ética, sobre la que tendríamos que manifestar serias reservas. Si la responsabilidad social no es para la empresa un mero instrumento para alcanzar buenos márgenes económicos, cabrá también aceptar que a veces la fidelidad a ese compromiso conlleve pérdidas, que no son sino "el coste de tener conciencia". Pero -tampoco seamos simplistas- no es ésta la única circunstancia en que la empresa opta por ganar "menos dinero" como precio para alcanzar otras metas.

\section{La agenda pendiente}

Para concluir estas reflexiones quisiéramos apuntar algunas tareas abiertas o líneas por las que convendría avanzar todavía. Varias de ellas han quedado ya apuntadas en todo lo que precede, lo que no excluye que volvamos a mencionarlas ahora.

Pero hay una cuestión que más arriba salió de pasada y sobre la que merece la pena volver ahora. En el pasaje que citamos de la Comisión de las Comunidades Europeas de 2001 se hablaba de "la integración voluntaria, por parte de las empresas". Aunque en los primeros momentos sorprendía que algo que se consideraba tan decisivo se dejase a la libre opción de cada empresa, poco a poco se ha ido imponiendo su carácter voluntario. Admitámoslo así, con tal que se entienda adecuadamente.

Esta propuesta podría relacionarse con la tendencia dominante hoy que propugna reducir en todo lo posible la intervención de los poderes públicos en la esfera económica. El debate autorregulación/heterorregulación encajaría aquí. Pero interpretar esta voluntariedad como pura discrecionalidad parece difícil de conciliar con todo lo dicho anteriormente sobre la génesis y la razón de ser del concepto. Como decíamos, aquí no se trata de una responsabilidad por la que se opta, sino de una responsabilidad que se asume porque existe previamente a toda opción nuestra. En todo caso, la voluntariedad habría que entenderla aquí como voluntariedad moral: como algo basado en una obligación moral, y no sólo en una norma jurídica. Esto supone admitir que 
el comportamiento moral no consiste sólo en cumplir normas sino además en asumir valores y actuar en coherencia con ellos.

Este enfoque voluntario es el que parece hacer suyo el Informe preparado en el Parlamento español. Son sintomáticas estas palabras que reflejan que el debate voluntariedad/regulación no está del todo cerrado:

Los diferentes comparecientes mantienen diferencias de criterio sobre el alcance y profundidad deseables de las iniciativas reguladoras en materia de RSE provenientes de las administraciones públicas, pero manifiestan una opinión generalizada de que puede resultar de utilidad el que las distintas Administraciones impulsen un marco promocional y un clima estimulador de la RSE, en línea con las experiencias exitosas que ya existen en varios países ${ }^{13}$.

Ese "marco promocional" y "clima estimulador" se concreta luego diciendo que las administraciones públicas pueden desempeñar un papel regulador $o$ un papel más facilitador y promotor ${ }^{14}$. Pero las sugerencias de regulación no van muy lejos y se limitan más bien a normas que estimulen su desarrollo premiando o beneficiando a las empresas que adoptan iniciativas de responsabilidad social.

Nosotros creemos que la responsabilidad social de la empresa debe desarrollarse en el marco de una adecuada articulación y colaboración entre Estado, mercado y sociedad civil. Pretender resolver el problema sólo desde la contraposición Estado/mercado, viendo además en el primero un factor distorsionador de la actividad económica, nos parece un camino errado. Ese fue el planteamiento de fondo de la etapa en que los dos grandes sistemas socioeconómicos se enfrentaron: el capitalismo liberal y el colectivismo marxista. El colectivismo fracasó irremisiblemente, mientras que el modelo más humanizador de capitalismo (el Estado social) entró en una profunda crisis. Pretender salir de la situación volviendo los ojos al capitalismo de mercado puro de antaño no tiene sentido. Tampoco retomar la vieja discusión de si más o menos mercado o más o menos Estado. Más bien hay que incluir un tercer actor, que es la sociedad civil, no para que sustituya a los dos anteriores, sino para que los complemente.

¿En qué se traduciría esta propuesta? Por lo pronto en un ambiente marcado por la colaboración y no por el enfrentamiento. No son tres instancias opuestas entre sí; el desarrollo de las funciones de cada una no se hace a costa del de

13 L. c., 112.

14 L. c., 115. 
las otras. Concretamente la responsabilidad es de la empresa: responde ante la sociedad y ante el Estado, pero a ambos corresponde facilitar, cada uno desde su identidad, el ejercicio de esa responsabilidad.

Para esto es preciso que existan cauces de encuentro y de participación a diferentes niveles. Con esto volvemos a subrayar lo que ya quedó dicho: que no conviene circunscribirse a lo social y a lo mediambiental: hay que abrirse a otros stakeholders, identificándolos en primer lugar y estableciendo cauces diferenciados de encuentro, diálogo y participación.

Pero tampoco se puede eliminar del todo la función normativa del Estado en su dimensión estrictamente coactiva. No se olvide que están en juego, entre otras cosas, los derechos humanos, sobre todo los sociales. Y es responsabilidad del Estado velar para que estos no sean violados. Téngase en cuenta un sano principio de realismo: en sociedades como las nuestras no es posible confiarlo todo a la buena voluntad y a la ética libremente asumida por las personas y las instituciones.

La mejor forma de articular heterorregulación y autorregulación puede tener su apoyo en una correcta comprensión de lo que es la ética. En ella caben las normas, que establecen mínimos obligatorios para todos; $y$, aunque no todo lo que es norma ética puede convertirse en norma legal, un cumplimiento básico de aquéllas exige alguna intervención selectiva y estratégica del poder legislativo del Estado. Pero la ética es más que normas, es apertura al mundo de los valores, y esto supone un horizonte de posibilidades de actuación nunca del todo consumadas. Si entendemos la responsabilidad social en el sentido proactivo que indicábamos más arriba, jamás se podrá decir que una organización pueda darse por satisfecha con lo que ha hecho en este campo.

Resumiendo, el carácter voluntario de la responsabilidad social no es una forma de eludir el control de los poderes públicos ni de contribuir a la reducción del Estado, no es tampoco pura liberalización y desregulación. Es asumir todas las responsabilidades derivadas del poder de que hoy disponen las organizaciones en general y en particular las empresas, y hacerlo como una oportunidad para desarrollar las funciones que la sociedad asigna a estas instituciones, contando con la colaboración del Estado y de toda la sociedad civil y rindiendo cuentas a todos los interlocutores sociales. 


\section{Una palabra final sobre el marco último de comprensión}

Hemos hablado al principio de diferentes modelos de empresa. Y hemos desarrollado este análisis de forma descriptiva, identificando los modelos que en la historia de este último siglo se han ido de hecho sucediendo. Al concluir estas reflexiones es oportuno subrayar el momento valorativo que deriva de este análisis. Porque no todos los modelos son éticamente equivalentes. Detrás del interés por la responsabilidad social hay una innegable opción por un modelo de empresa: aquel que se estructura sobre una red de interacciones expresamente asumidas como motor para el desarrollo de sus actividades y el cumplimiento de su función. Aunque las dos revoluciones citadas (la de los directivos y la de los accionistas) aportaron elementos irrenunciables para comprender la empresa, ninguna de ellas suministró un modelo adecuado para comprender a esta en toda su complejidad. El recurso a los stakeholders y el concepto de responsabilidad social permiten perfilar un nuevo modelo que responde mejor a lo que es la empresa en la realidad social, y sobre todo en el mundo globalizado. Por eso es un modelo éticamente preferible y es la mejor base para programar y desarrollar toda la actividad de la empresa $y$, por extensión, de cualquier otra organización.

Pero detrás de la responsabilidad social y de este modelo de empresa hay más: hay una forma de entender la sociedad por la que también queremos apostar. Tres rasgos destacamos: es una sociedad compleja, que no se adapta a ciertas simplificaciones al uso; debe articular sus tres grandes componentes (el mercado, el Estado, la sociedad civil); sin negar los conflictos inevitables, debe basar esa articulación en un principio de colaboración. 